\title{
UTILIZANDO A CRIATIVIDADE NA EDUCAÇÃO EM SAÚDE EM ALOJAMENTO CONJUNTO NEONATAL: OPINIÃO DE PUÉRPERAS SOBRE O USO DE UM JOGO EDUCATIVO ${ }^{1}$
}

\author{
CREATIVITY IN HEALTH EDUGATION IN A NEONATAL ROOMING-IN: \\ OPINION OF PUERPERS ON THE USE OF AN EDUCATIONAL GAME \\ UTILIZANDO LA CREATIVIDAD EN LA EDUCACIÓN EN SALUD EN \\ ALOJAMIENTO CONJUNTO NEONATAL: OPINIÓN DE PUÉRPERAS \\ SOBRE EL USO DE UN JUEGO EDUCATIVO
}

\author{
Luciana Mara Monti Fonseca ${ }^{2}$ \\ Carmen Gracinda Silvan Scochi ${ }^{3}$ \\ Cláudia Elizângela Fernandez Bis ${ }^{2}$ \\ Sueli Olivia Andreo Serra ${ }^{2}$
}

\begin{abstract}
RESUMO: O estudo objetiva descrever a vivência do enfermeiro no desenvolvimento e utilização de um jogo educativo sobre aleitamento materno e cuidados básicos com o recém-nascido, junto à puérperas em alojamento conjunto e identificar as opiniöes das mäes sobre essa vivência. Estudo descritivo realizado em uma maternidade filantrópica de Ribeiräo Preto -SP. Atividades educativas foram realizadas em grupo, coordenadas pela enfermeira, utilizando jogo de tabuleiro. Estimula-se a participação de outras mães para completar respostas às questões formuladas e, ao final, solicitase opinião sobre a vivência. Das opiniōes verbalizadas verificamos: as mães consideram o jogo "divertido", "estimulante", deixando-as atentas pois "numa aula normal todas iriam dormir" e "quebra a rotina do hospital". A dinâmica utilizada tornou "mais fácil perguntar sobre as dúvidas, sem vergonha", "todo mundo dá opinião" e facilita a aprendizagem ("mais fácil de aprender", "mais fácil de guardar"). Concluimos que o jogo constitui estratégia adequada para facilitar troca de experiências entre puérperas e o desenvolvimento da educação em saúde através de atividades lúdico-pedagógicas.
\end{abstract}

PALAVRAS-CHAVE: alojamento conjunto, educação em saúde, jogo educativo

\section{INTRODUÇÄO}

O alojamento conjunto tem como objetivo a integração mais intima da mãe com o recémnascido (RN) contribuindo para: estabelecer um relacionamento afetivo favorável entre mãefilho, desde o nascimento; educar a mãe e o pai, desenvolvendo habilidades e proporcionando segurança emocional quanto aos cuidados com o bebê; incentivar o aleitamento materno; reduzir a incidência de infecçōes hospitalares cruzadas; permitir à equipe de saúde melhor integração e observação sobre o comportamento normal do binômio mãe-filho (BRASIL, 1982, Corradini et al., 1991).

\footnotetext{
'Trabalho apresentado no $51^{\circ}$ Congresso Brasileiro de Enfermagem e $10^{\circ}$ Congreso Panamericano de Enfermeria, Florianópolis - SC, 1999.

${ }^{2}$ Enfermeiras mestrandas do Programa de Pós-Graduação - Área Enfermagem em Saúde Pública, da Escola de Enfermagem de Ribeiräo Preto - USP.

${ }^{3}$ Profa. Dra. do Departamento de Enfermagem Materno-Infantil e Saúde Pública, da Escola de Enfermagem de Ribeirão Preto - USP.
} 
O alojamento conjunto permite ainda uma renovação dos profissionais da saúde no seu contexto de atuação, pois, dentro de um novo e mais amplo conceito de saúde materno-infantil, o ato de curar e cuidar não é atividade exclusivamente dos profissionais da saúde, mas inclui a co-participação daquele que é tratado e curado. Esta acepção oriunda do espírito da Pediatria Social transforma a maternidade de agência de assistência técnica de manutenção da saúde em centros de educação sanitária de longo alcance. A mãe ensinada a se cuidar, a entender o filho, a satisfazer suas necessidades integrais, torna-se agente multiplicador da saúde em âmbito individual, familiar, social e ecológico.

Dentre as vantagens desse sistema enfatizamos a educação em saúde. Este sistema deve constituir um centro natural de educação e não um local de acomodação de pessoas. Não é um método de assistência utilizado para economizar pessoal de enfermagem, pois tem um alto conteúdo educativo que precisa ser considerado prioritário (BRASIL, 1982).

Neste sentido, durante o tempo de permanência no hospital, é vantajoso que a mãe seja ensinada a cuidar do bebê, sob a orientação direta da enfermeira, bem como o pai deve participar de algumas aulas e dispensar cuidados à criança, para conhecê-la melhor e poder auxiliar a esposa, após a alta hospitalar. Isto aumenta a segurança dos pais e melhora o relacionamento familiar.

Todavia, nem todas as maternidades desenvolvem atividades educativas regularmente. Scochi et al. (1996), analisando o trabalho em duas maternidades do municipio de Ribeirão Preto - SP constataram que na instituição privada não havia ações educativas sistematizadas, pois estas dependiam das peculiaridades das atententes de enfermagem, sendo que a maioria demonstrou um trabalho normativo, mecanizado, inespecifico e de certa forma autoritário. Na instituição pública havia intervenções educativas sistematizadas, as atendentes e auxiliares de enfermagem faziam orientações individuais ou em pequenos grupos sobre os cuidados básicos com o RN; a enfermeira fazia orientações em grupos com as puérperas utilizando como recurso um álbum de fotos coloridas e apostila sobre o aleitamento. Verificaram também, inadequações e deficiências quantitativas nas atitudes e capacitação dos profissionais de saúde para manejarem as inter-relações para com a clientela, sendo recomendado um esforço das instituições de ensino e assistenciais no sentido de capacitarem seus recursos humanos e contratarem os agentes necessários, bem como instrumentalizá-los com conhecimentos mais abrangentes sobre interação mãe-filho, relações familiares e técnicas educativas, a fim de desenvolverem habilidades para atenção integral à saúde.

Sabemos das dificuldades e escassez de recursos que vivenciam grande parcela dos serviços de saúde. Por outro lado, não é possivel ficarmos imobilizados até que mudanças macro-estruturais e sociais ocorram. Na prática cotidiana em alojamento conjunto há espaço para desenvolvimento de atividades criativas, visando a melhoria da qualidade da assistência de enfermagem.

Cabe ressaltar que a criatividade é o casamento da arte e da ciência na enfermagem; é a sintese verdadeira da ciência, arte, teoria e práticas, cujos resultados em todas as enfermeiras são o pensar e o agir (Fawcet et al., 1997).

Em diferentes partes do mundo, o cuidar de pessoas tem inspirado desde adequações de outros produtos existentes, passando pela improvisação de alguns outros, até a resposta mais efetiva de intencionalmente projetar e desenvolver produtos de interesse para a vida e para a saúde. Esse aspecto da enfermagem é tão interessante que se manifesta, tanto em paises ditos de primeiro mundo como nos rotulados terceiro-mundistas. Parecendo mesmo que esse caminho tem sua nascença na qualidade que vem das pessoas e sugerem como medida de capacidade a intensidade da força criadora (Dias et al., 1996).

Nesta perspectiva é que nos sentimos estimuladas em desenvolver estratégias criativas na educação em saúde de puérperas em alojamento conjunto.

Vislumbrando a possibilidade de construir com a mãe, conhecimentos acerca dos cuidados 
com $\mathrm{RN}$ e o aleitamento materno, num esforço para o preparo mais adequado da alta hospitalar, elaboramos um jogo educativo para instrumentalizar nossa prática educativa em alojamento conjunto neonatal.

Assim, motivamo-nos realizar o presente estudo tendo por base nossa vivência no desenvolvimento e utilização de material didático-pedagógico inovador, para facilitar e dinamizar o processo de ensino-aprendizagem junto à puérperas.

Esperamos com isso, fornecer subsidios para a organização da prática de enfermagem em alojamento conjunto, através da utilização de tecnologia simplificada em atividades educativas, rumo ao processo de construção de uma assistência integral mais criativa e participativa.

\section{OBJETIVOS}

- Descrever a vivência do enfermeiro no desenvolvimento e utilização de um jogo educativo sobre aleitamento materno e cuidados básicos com o recém-nascido, junto à puérperas em alojamento conjunto.

- Identificar as opiniões das mães sobre essa atividade de educação em saúde mediada pela utilização do jogo educativo.

\section{METODOLOGIA}

O estudo foi realizado em uma maternidade filantrópica do municipio de Ribeirão Preto SP, a qual possui 44 leitos de alojamento conjunto e destina-se a assistência ao parto de baixo risco da clientela usuária do Sistema Único de Saúde. É campo de estágio de alunos de graduação em enfermagem e constitui local onde os docentes da Escola de Enfermagem de Ribeirão Preto, da Universidade de São Paulo, desenvolvem atividades de extensão de serviços à comunidade. A permanência da clientela nesta maternidade é curta, em torno de 24 horas após o parto.

Para aprimorar as atividades de educação em saúde, criamos um jogo educativo para discussão, em grupo de puérperas, de temas relacionados à amamentação como cuidados com as mamas, traumas mamilares e direitos da mãe que trabalha, bem como conteúdos relativos aos cuidados com o RN como curativo do coto umbilical, higiene corporal, banho de sol, vestuário, teste do pezinho, cólica e choro. As questões que direcionam a atividade lúdicopedagógica abordam sobre essas temáticas de maneira mais diretiva ou indiretamente ao conterem afirmações ou questionamentos sobre alguns mitos presentes no cuidado do bebê.

O jogo educativo é constituido de: um tabuleiro colorido com percurso dividido em 26 caselas, tendo ponto de saida e chegada dos jogadores; 50 cartas contendo perguntas sobre as temáticas citadas e, no verso, as respectivas respostas; dois dados e marcadores (peões) coloridos representando cada jogador ou dupla. O número mínimo de jogadores é 4 e o máximo 12, formando-se duplas caso o número de jogadores seja superior a 5.

Na dinâmica, cada participante ou dupla retira uma carta e se acertar a questão, caminha no tabuleiro o número de casas correspondente à soma de pontos obtida no lançamento dos dados. Ganha o jogo aquela(s) que chegar(em) primeiro ao final do percurso. Estimula-se participação de outras mães para completar as respostas às questões formuladas.

Por tratar-se de um estudo descritivo, discorremos sobre nossa vivência na utilização desse jogo educativo como estratégia de Educação em Saúde para orientações das puérperas em alojamento conjunto.

Para atender ao segundo objetivo do estudo, opinião das puérperas sobre essa vivência, a amostra constituiu-se das participantes em 3 grupos de atividade educativa: no $1^{\circ}$ grupo participaram 11 puérperas, no $2^{\circ}-10$ e no $3^{\circ}-09$, totalizando 30 puérperas com idade variando de 14 a 39 anos. 
Ao final de cada grupo educativo, as mães foram estimuladas a expressarem suas opiniões acerca do uso do jogo como estratégia de ensino-aprendizagem, as quais foram registradas em um diário de campo, sob a forma de relato cursivo, mantendo-se as expressões de linguagem utilizadas por elas.

As puérperas consentiram em participarem do estudo e, para preservar o sigilo, as falas foram identificadas da seguinte forma: puérpera $(p)$, seguida de um numeral relacionado ao grupo pertencente $(1,2$ e 3) e, no final, uma letra conforme cronologia das opiniões verbalizadas. Assim, p1.a refere-se a primeira (a) puérpera (p) do $1^{\circ}$ grupo (1).

Para análise dos dados, utilizamos a técnica de Análise de Conteúdo, modalidade Análise Temática, com base em Minayo (1994). Para a autora fazer a Análise Temática de um determinado texto resume-se em desvelar os núcleos de sentido que fazem parte da comunicação, cuja presença tem alguma representação para o objeto definido.

\section{RESULTADOS E DISCUSSÃO}

A atividade lúdico-pedagógica desenvolvida para puérperas foi idealizada a partir da necessidade de passar informações de forma dinâmica, com a participação efetiva delas na construção dos seus conhecimentos.

Piaget citado por Macedo (1995), relata que os jogos podem ser estruturados basicamente segundo três formas: exercicio, símbolo ou regra. As três estruturas de jogos são caracterizadas segundo sua forma típica de assimilação.

Classificamos nosso jogo como sendo de regra, o qual, segundo Piaget, tem o caráter coletivo como algo original e próprio de sua estrutura. Ou seja, nessa estrutura só se pode jogar em função da jogada do outro, portanto, os jogadores sempre dependem um do outro. Por isso, a idéia de assimilação recíproca. No sentido de coletividade e de uma regularidade intencionalmente consentida ou buscada, e ainda pelas convenções que definem o que os jogadores podem, ou não, fazer no contexto do jogo. O tempo, o espaço e os critérios de ganho ou perda são limites, ainda que arbitrários, que regulam as condutas recíprocas dos participantes do jogo. Do ponto de vista funcional, essa forma de jogo é importante porque atualiza, mas com um sentido simbólico e operatório, o jogo de significados, porque, para ganhar, o jogador tem que competir em um contexto no qual, por princípio, seu oponente tem as mesmas condições (Macedo, 1995).

As atividades educativas foram realizadas em grupo, coordenadas pela enfermeira, e tiveram duração média de uma hora.

Durante a realização das atividades educativas, algumas condutas foram tomadas, a saber:

- Estimulou-se que outras participantes ajudassem nas respostas, trazendo suas experiências.

- Sugeriu-se que fizessem outras perguntas não contidas no jogo, para sanar dúvidas.

- Estimulou-se a participação dos pais ou parentes que estavam presentes durante a atividade grupal de educação em saúde, formando duplas ou trios.

- O enfermeiro que coordenava o grupo teve a tarefa de ler todas as fichas, para evitar o constrangimento das jogadoras analfabetas.

Percebemos que as mães, frente ao jogo, ficavam mais descontraidas; as mais tímidas eram, por nós, estimuladas a expor suas experiências passadas, positivas e negativas. $\mathrm{O}$ fato das outras participantes relatarem suas experiências fez com que as tímidas se sentissem a vontade para se colocar também. Quando começavam a abordar sobre as dúvidas, que sentiam vergonha de exteriorizar, e percebiam que estas eram também de outras participantes, elas se sentiam mais à vontade para colocá-las para o grupo.

Consideramos relevante e estimulamos a obtenção de respostas às perguntas formuladas 
a partir da experiência do próprio grupo, dos conhecimentos obtidos da relação com as suas próprias mães e sogras, vislumbrando a elucidação de problemas e tabus a partir do seu próprio meio, da realidade que as cercam. Os comportamentos de risco para o auto-cuidado e o cuidado com o RN eram discutidos, reforçando as atitudes positivas verbalizadas por algumas puérperas.

Segundo Milet e Marconi (1992), a ação educativa é como um projeto que visa alcançar resultados internos e externos através de um processo participativo dos educandos. Tais resultados correspondem à apreensão e incorporação de capacidades, valores, habilidades e atitudes exercitadas e desenvolvidas individualmente no processo grupal, onde se destacam: compromisso, reflexão, comunicação, confiança, flexibilidade, auto-estima, cooperação, concentração, objetividade, expressividade e criatividade. Na prática, o coordenador, que é o profissional da saúde, tem a função de orientar e facilitar o processo de ensino-aprendizagem, de maneira a promover as condições ideais para que os resultados ocorram através de seus conhecimentos sobre a linguagem utilizada nas técnicas de trabalho de grupo, nos vinculos que ai estabelecem, bem como estimular a participação de seus integrantes. Dentro da dinâmica de trabalho em grupo desenvolvem-se ações educativas e através de materiais educativos que demonstram o esforço de todo o grupo, no sentido de explorar, decifrar, registrar, confrontar seus sentimentos, pensamentos e capacidade de realizações no atendimento de suas necessidades e a dos outros.

Essa experiência nos oportunizou desenvolver a atividade de educação em saúde de maneira descontraída e criativa, utilizando de recursos não usuais desta prática, estimulando a participação efetiva tanto das puérperas como de outros profissionais (residentes, enfermeiros e alunos de enfermagem) que percebiam as mães demonstrando e verbalizando os beneficios de aquisição de conhecimento e a descontração após a participação na atividade educativa. Isso nos motivou a aperfeiçoar o jogo piloto, confeccionando-o em material de maior resistência e ampliando o conteúdo de perguntas e respostas.

Percebemos durante a execução das atividades educativas atitudes de descontração. Antes da criação deste jogo, esta atividade era monótona, desestimulante, repetitiva, tornandoa desinteressante para o educador/enfermeiro. Atualmente, sentimo-nos empenhadas e motivadas para desenvolver esta prática, utilizando uma estratégia que permite a participação do grupo na criação do conhecimento.

Da a análise qualitativa das opiniões verbalizadas pelas mães sobre essa vivência, identificamos seis temas que se apresentaram de forma mais marcante, conforme descrição que se segue.

\section{Descontrai e muda a rotina hospitalar}

O fato de participarem de um grupo, envolvendo-se, desenvolve nos individuos um sentido de auto realização, de ser importante, mobilizando o lado construtivo de suas personalidades. Traz maior auto confiança e um auto conceito positivo, se pensado que todas as mäes participam da construção dos seus próprios conhecimentos, trazendo troca de experiências e oportunidade de auto expressão (Mendes, 1996).

Kishmoto (1996a) relata que, na maioria das vezes, o ato lúdico se contrapõe ao trabalho, considerado atividade séria, mas, o caráter "não sério" não implica que a brincadeira deixe de ser séria. A pouca seriedade a que faz referência está mais relacionada ao cômico, ao riso, que a acompanha. Quando brinca, a pessoa toma certa distância da vida cotidiana, entra no mundo imaginário.

A participação nessa atividade possibilita modificações no modo de enxergar a vida, no modo de agir e de sentir. As pessoas ao sairem de seu mundo restrito, onde se entregam às dores provenientes do periodo pós-parto, adquirem novas perspectivas, o que reduz a medicalização dos fenômenos fisiológicos da maternidade. 
Exemplos desta categoria:

...interessante... (p1.c)

...com o jogo é melhor... (p3.c)

...descontrai, a gente esquece tudo... (p3.h)

...mais divertido, mais descontraido... (p3.d)

Observamos também que os benefícios extrapolam as questões acima colocadas quando a atividade proposta modificou a dinâmica hospitalar, normalmente muito rotineira, técnica e monótona, tornando o hospital também em um espaço de diversão:

...quebra a rotina... (p1.b).

Horta (1991) aborda que na monotonia das tarefas executadas pelas mães abre-se espaço para o tédio, a dor, o sofrimento, a culpa. É preciso buscar alternativas conjuntas (entre profissionais de enfermagem e a mãe) de transformação desta realidade.

\section{Desperta atenção e estimula o aprendizado}

Para Antunes (1999), durante muito tempo confundiu-se "ensinar" com "transmitir" e, nesse contexto, $o$ indivíduo que aprendia era um agente passivo da aprendizagem, e o que ensinava era um transmissor não necessariamente presente nas necessidades do aprendiz. Acreditava-se que toda aprendizagem ocorria pela repetição e que os que não aprendiam eram responsáveis por essa deficiência. Atualmente, sabe-se que não existe ensino sem que ocorra a aprendizagem, e que esta não acontece senão pela transformação, pela ação facilitadora do ensinador e pelo processo de busca do conhecimento, que deve sempre partir do aprendiz. A idéia de um ensino despertado pelo interesse do aprendiz acabou transformando o sentido do que se entende por material pedagógico e cada aprendiz, independente de sua idade, passou a ser um desafio à competência do ensinador. Seu interesse passou a ser a força que comanda o processo da aprendizagem e as suas experiências e descobertas transformou-se em motor de seu progresso; o ensinador passou a ser um gerador de situações estimuladoras e eficazes. É nesse contexto que o jogo ganha um espaço como ferramenta ideal da aprendizagem, na medida em que propõe estímulo ao interesse do aprendiz. $\mathrm{O}$ jogo ajuda-o a construir suas novas descobertas, desenvolve e enriquece sua personalidade e simboliza um instrumento pedagógico que leva ao ensinador a condição de condutor, estimulador e avaliador da aprendizagem.

Exemplos desta categoria:

...é mais estimulante... (p2.c)

...desperta mais a atenção... (p2.a)

...se fosse uma aula normal todo mundo ia dormir... (p2.e)

....assim é mais fácil de aprender, de gravar... (p1.d)

\section{Mobiliza competição}

Os jogos de regra em uma perspectiva funcional apresentam caráter competitivo e valorizam o espírito de competição e, por extensão, a individualidade. A competição em si não é má, nem boa, mas caracteriza uma forma de problematização universal na vida. Competir (do latim competere) significa pedir simultaneamente a mesma coisa; no jogo de regras os jogadores fazem ao mesmo tempo um único pedido: ganhar. A competição caracteriza-se por uma estrutura assimétrica, de diferença, porque nesse sistema não tem um para cada um, ou tudo para todos, mas sim uma relação de um para muitos. $E$, como as estruturas simétricas ou de igualdade, a competição é uma estrutura universal que descreve uma forma de problematização das coisas em um sistema. No entanto, o que modifica o sentido da competição em diferentes 
contextos é o modo como se reage a ela, é o que se faz diante dela. Assim, o que se critica não é a competição em si mesma, mas as formas culturais, políticas etc. de se reagir diante dela. Outro significado funcionalmente importante para a competição é o da competência, da habilidade pessoal ou talento para enfrentar problemas e resolvê-los da melhor forma possivel. Ser competente é uma situação desafiadora, em que, por suas caracteristicas, só um lado pode ganhar, o que não significa ser individualista, ao menos nos jogos de regra. Nesses jogos, as condições, as regras etc. são as mesmas para todos: que o melhor seja o vencedor. E se a competência for a mesma, que seja vencedor quem tiver mais sorte. A competência é o desafio de ser melhor do que si mesmo. Nessa perspectiva, o ganhar e o perder são sempre ganhar e perder de si próprio (Macedo, 1995).

Exemplos desta categoria:

...divertido, a gente fica ansiosa para ganhar... (p1.a)

.... a gente fica curiosa para sabe qual é a próxima pergunta... (p2.f)

...é uma competição e a gente fica louca para ganhar... (p2.h)

...falta um prêmio... (p2.d)

\section{Possibilita a expressão de dúvidas e opiniōes das participante}

No envolvimento das puérperas na atividade educativa houve troca de experiências acerca dos temas em discussão; "brincadeira" e "o jogar" garantiram a liberdade verbal, diminuindo o medo de se expor:

...todo mundo dá opinião... (p3.e) e (p3.i)

...todo mundo fala... (p3.f)

...no jogo, não tenho vergonha de perguntar minhas dúvidas, é mais fácil... (p1.e)

A ausência de pressão do ambiente cria um clima propicio para investigações necessárias à solução de problemas. Assim, jogar leva a pessoa a tornar-se mais flexivel e buscar alternativas de ação (Bruner et al., 1976).

Para Kishimoto (1996a), o brinquedo enquanto função educativa ensina coisas que completam o individuo em seu saber, seus conhecimentos e sua apreensão do mundo; a pessoa adquire noções espontâneas, em processos interativos, envolvendo-a por inteiro com suas cognições, afetividade, corpo e interações sociais.

O jogo de regra permite, criar uma situação que libera os limites do real. Essa situação frivola diante da parada das obrigações e condições da vida cotidiana, surge como um espaço único de experiências para aquele que brinca (Bruner et al., 1976).

É importante registrar que a riqueza do conteúdo discutido durante o jogo provém de experiências anteriores, adquiridas pelas participantes, em diferentes contextos. A aquisição de idéias e ações provêm do mundo social, incluindo a família e o círculo de relacionamento. Os conteúdos veiculados durante o jogo, paralelo às cartas (perguntas formuladas), bem como as oportunidades para interações sociais são todos fatores que dependem basicamente de cada grupo e do profissional que o conduz.

\section{Acresce conhecimento}

Na décadas de 20 Claparède e Decroly criaram uma das pedagogias mais modernas, a única que integra realmente o jogo no ensino: os jogos educativos (Michelet, 1996).

Para Macedo (1995) os jogos educativos, do ponto de vista estrutural, têm importância capital para a produção do conhecimento. O sentido e a necessidade de teoria (do esforço humano de explicar as coisas, de dar respostas ainda que provisórias para as perguntas que nos faz o jogo da vida) formulam-se e ganham contexto nos jogos. Em outras palavras, as fantasias, as mitificações, os modos deformantes de pensar ou inventar a realidade são como 
prelúdio para futuras teorizações. Em sintese, os jogos são a base para o como e o porque das coisas.

Segundo Kishimoto (1996b), o ato lúdico representa um primeiro nivel de construção do conhecimento, o nivel do pensamento intuitivo, ainda nebuloso, mas que já aponta uma direção. O prazer e a motivação que envolvem a ação lúdica iniciam o processo de construção do conhecimento.

Ao participarem da atividade e terem acesso às informações e aos "porquês", as mães expressaram que não haviam, em tempo algum, perguntado o "porquê" das orientações recebidas, o que as tomavam meras cumpridoras de ordens. Isto nos remete a pensar na verticalização e dominância em que se apresentam os programas de Educação em Saúde, vindos com o surgimento da puericultura, no século XIX, em que os médicos pediatras vislumbravam a hegemonia de sua classe, não aconselhando, mas dando ordens às mães, "domesticando-as". Nesse contexto, a Educação em Saúde assume o papel de transmissora de conhecimento "dos que sabem" "para os que não sabem" (pedagogia tradicional).

Em contraponto à "pedagogia tradicional", centramos nosso estudo na pedagogia moderna - teoria construtivista, no qual o aprendiz é o agente ativo do seu próprio conhecimento. Exemplos desta categoria:

...esclarece as dúvidas... (p2.b)

...eu nunca perguntei porque cura o umbigo... (p2.i)

...eu nunca perguntei, nem me falaram... (p2.j)

....isso que é peito empedrado... (p3.g)

...aprendi muita coisa hoje... (p3.a)

...agora eu sei como cuidar... (p3.b)

...eu não vou deixar a minha mãe falar que o meu leite é fraco... (p2.g)

\section{CONSIDERAÇÖES FINAIS E RECOMENDAÇÖES}

Através dos resultados apreendemos que o jogo educativo, enquanto uma nova estratégia para educação em saúde, contribuiu para ampliar o conhecimento das mães sobre a relevância do aleitamento materno, o auto cuidado com a mama puerperal e os cuidados básicos com o RN. Houve troca de experiências entre os participantes, aquisição de conhecimentos e abertura para discussão de mitos e atitudes de risco para a saúde da puérpera e do bebê.

Todavia, a metodologia utilizada não assegura mudanças dos comportamentos de risco das mães, dado a complexidade de fatores envolvidos neste processo.

O jogo educativo foi considerado pelas mães como estratégia divertida e estimulante, deixando-as mais atentas e soltas, abertas a aprender e a ensinar.

Acreditamos que o estudo pode contribuir com o preparo técnico dos profissionais de saúde com vistas à assistência integral em alojamento conjunto suscitando, nestes, o desejo de ousar, de criar, partindo do pressuposto que o jogo educativo aqui empregado apresenta tecnologia simplificada, artesanal, manufatura barata e acessivel.

Cabe assinalar que a nossa experiência de intervenção, embora válida, deve estar inserida em um projeto maior de Educação em Saúde a ser trabalhado pelos setores sociais envolvidos com a formação dos cidadãos. Vários aspectos das temáticas como aleitamento, maternidade/ paternidade, auto-cuidado e cuidados com o bebê deveriam ser discutidos durante a escolarização, no planejamento familiar, pré-natal e seguimento na rede básica de saúde, na perspectiva do continum da assistência no processo de crescimento e desenvolvimento do ser humano. 
ABSTRACT: The article presents the experience of nurses in the development and use of an educational game on breastfeeding and basic care with the newborn with a group of puerperae women in a rooming-in unit, the analyzing the opinions of the participants involved in the educational experience. This descriptive study which was carried out at a philanthropic maternity in Ribeirão Preto, São Paulo. The educational activity proposed was a board game, coordinated by a nurse, in which mothers were organized in two groups. One group formulated questions on breastfeeding and basic care of the newborn, while the other group answered the questions. At the end of the game the participants were requested to give their opinion about the activity. The results show that the mothers considered the game entertaining and stimulating. It broke the hospital's routine, kept the "players" attentive and facilitated understanding and learning under discussion of the subject. The authors conclude that the activity proposed was an appropriate strategy to facilitate the exchange and learning under discussing of experiences among mothers, as well as, to develop health education through the use of ludicaleducational games.

KEYWORDS: rooming-in, health education, educational games.

RESUMEN: El estudio describe la vivencia del enfermero al desenvolver y utilizar un juego educativo sobre el tema amamantación materna y los cuidados básicos con el recién nacido para puérperas en un alojamiento conjunto e identificar las opiniones de las madres sobre esa vivencia. Se hizo en una maternidad filantrópica de Ribeiräo Preto-SP. Las actividades educativas se realizaron en grupo, coordinadas por la enfermera utilizando un juego de tablero. Se estimula la participación de otras madres para completar las respuestas y al final se les pide que opinen sobre la experiencia. De las opiniones verbalizadas, se verifica que: las madres consideraron el juego divertido, estimulante, y estuvieron atentas; "si hubiese sido una clase normal se hubieran dormido" y que les sirvió para "romper la rutina del hospital". Con la dinámica utilizada fue "más fácil sacar las dudas, sin tener vergüenza", "todas pueden dar su opinión" y facilita el aprendizaje ("más fácil de aprender", "más fácil de guardar"). Se concluye que el juego constituye una estrategia adecuada para ffacilitar el cambio de experiencias entre puérperas y el desarrollo de la educación en salud, a través de actividades lúdico-pedagógicas.

PALABRAS CLAVE: alojamiento conjunto, educación en salud, juego educativo

\section{REFERÊNCIAS BIBLIOGRÁFICAS}

ANTUNES, C. Jogos para a estimulação das múltiplas inteligências. Petrópolis: Vozes, 1999.

BRASIL. Ministério da Saúde. I Encontro Nacional sobre Alojamento Conjunto. Relatório Final. Brasília: Ministério da Saúde/INAN, 1982.

BRUNER, J. et al. Play. its role in development evolution. New York: Penguin Books, 1976. (mimeogr.).

CORRADINI, H.B. et al. Cuidados ao recém-nascido em alojamento conjunto. In: MARCONDES, E. Pediatria básica. 8. ed. São Paulo: Saraiva, 1991. Seção 2, p. 315-6.

DIAS, L.P.M. et al. Potencial, talento e expressão artística: a enfermagem verbo criar. Texto Contexto Enfermagem, v.5, n. 1, p. 46-63, 1996.

FAWCETT, J. et al. Commentary about Levine's on creativity in nursing. Jornal of Nursing Scholarship, v. 29, n. 3, p. $4-6,1997$. 
HORTA, A.L.M. O alojamento conjunto pediátrico: a inserçăo do familiar, o trabalho do enfermeiro e outras questōes. São Paulo, 1991.58p. Dissertação (mestrado) - Escola de Enfermagem, Universidade de São Paulo.

KISHIMOTO, T.M. Jogo, brinquedo e brincadeira. In: CARVALHO, A.M.P. et al. O coordenador pedagógico identidade em construção - O jogo e a construção do conhecimento. São Paulo: Secretaria Municipal da Educação, 1996a. p. 7-16.

KISHIMOTO, T.M. Bruner e a brincadeira. In: CARVALHO, A.M.P. et al. O coordenador pedagógico: identidade em construção - O jogo e a construção do conhecimento. São Paulo: Secretaria Municipal da Educação, 1996b. p. 39-42.

MACEDO, L. Os jogos e sua importảncia na escola. Cad. Pesq., n. 93, p. 5-10, 1995.

MENDES, I.J. M. Promoçäo de saúde: caminho para o único. Ribeirăo Preto, 1996. Tese (LivreDocência) - Escola de Enfermagem de Ribeirăo Preto, Universidade de São Paulo.

MICHELET, A. El maestro y el juego. In: CARVALHO, A.M.P. et al. O coordenador pedagógico identidade em construçăo - O jogo e a construçăo do conhecimento. Săo Paulo: Secretaria Municipal da Educação, 1996. p. 43-55.

MILET, M.E., MARCONI, R. Metodologia participativa na criação de material educativo com adolescentes. Salvador: Paulo Dourado, 1992.

MINAYO, M. C. S. O desafio do conhecimento. Pesquisa qualitativa em saúde. 3. ed. São Paulo Hucitec/Abrasco, 1994.

SCOCHI, C.G.S et al. O alojamento conjunto em hospitais-maternidade do município de Ribeirão Preto: análise da assistência. Acta Paul. Enfermagem, v.9, n.3, p.15-23, 1996. 